\title{
Isolation and Structural Elucidation of a Peptide Derived from Edam Cheese that Inhibits $\beta$-Lactoglobulin Transport
}

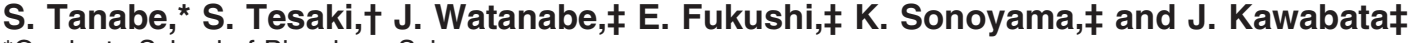 \\ *Graduate School of Biosphere Science, \\ Hiroshima University, \\ Hiroshima 739-8528, Japan \\ †Department of Food and Life-Science, \\ Takasaki University of Health and Welfare, \\ Takasaki 370-0033, Japan \\ ‡Graduate School of Agriculture, \\ Hokkaido University, \\ Sapporo 060-8589, Japan
}

\begin{abstract}
A peptide that inhibits $\beta$-lactoglobulin absorption in an in vitro Caco-2 cell model was isolated from Edam cheese. By ${ }^{1} \mathrm{H}-\mathrm{NMR}$ and N-terminal amino acid analyses, the active compound was identified as Asp-Lys-IleHis-Pro-Phe. The sequence of the hexapeptide is the same as the amino acid sequence of residues 47-52 of $\beta$-casein. The hexapeptide shows remarkable inhibition of $\beta$-lactoglobulin transport at a concentration of $10^{-7} \mathrm{M}$. The possibility exists that this peptide can be applied practically to the prevention of milk-sensitive allergy.
\end{abstract} (Key words: allergen absorption, $\beta$-lactoglobulin, Edam cheese, cow's milk allergy)

Abbreviation key: $\boldsymbol{\beta}$-Lg $=\beta$-lactoglobulin, DMEM $=$ Dulbecco's modified Eagle's medium, FCS = fetal calf serum, FITC = fluorescein isothiocyanate, HBSS = Hanks' balanced salt solution, ODS = octadecylsilyl, OVA $=$ ovalbumin, PBS $=10 \mathrm{~m} M$ phosphate buffered saline, TEER $=$ transepithelial electrical resistance, TFA = trifluoroacetic acid.

\section{INTRODUCTION}

Food allergy is one of the most important health problems in recent years, and cow's milk is a common allergy-inducing food (Jalonen, 1991; Savilahti and Kuitunen, 1992). $\beta$-Lactoglobulin ( $\beta$-Lg) has been identified as a major allergen in milk (Lebental, 1975; Bahna, 1985), and its epitope structure has been determined (Takahashi et al., 1988; Takahashi et al., 1990; Tsuji et al., 1993). Although milk is considered a desirable food for infants, cow's milk-sensitive allergic patients

\footnotetext{
Received April 24, 2002.

Accepted June 10, 2002.

Corresponding author: S. Tanabe; e-mail: stanabe@hiroshima-u. ac.jp.
}

must consume a milk-free diet. Thus practical methods, such as $\beta$-Lg-eliminated milk (Kuwata et al., 1985; Mate and Krochta, 1994), have been proposed to produce hypoallergenic milk for infants. Although the resulting hypoallergenic products probably contain a small quantity of remaining allergen, infants have never suffered allergic reactions, even when they drank the product continuously (Merritt et al., 1990). Because digestive function is underdeveloped in infants, they cannot completely digest milk proteins, and thus might produce peptides with allergy-preventing functions. Kaminogawa et al. (1999) reported that a peptide derived from $\beta$ - Lg efficiently inhibits the production of antibodies in an animal model via the immunological mechanism (called an oral tolerance) under which allergen-specific regulatory T-lymphocyte are essentially involved. In addition, an inhibitory function against allergen absorption from the intestinal tract would be expected. Here we present the first hypothesis that such functional peptides are produced by digestion of cow's milk in the intestinal tract, and that this leads to the resulting inhibition of allergic disorders.

It is probable that allergy-preventing peptides might exist in fermented milk products, such as cheese, since they contain large amounts of peptides. To search for allergen absorption inhibitors, we selected Caco-2 cells as a model of the intestinal tract. Caco-2 is a human colon adenocarcinoma cell line that exhibits various enterocytic characteristics such as intercellular tight junctions, nutrient transporters, and brush-border enzymes (Pinto et al., 1983; Hidalgo et al., 1989). This paper describes the isolation and structural elucidation of a $\beta$-casein-derived peptide with inhibitory activity against $\beta$-Lg absorption.

\section{MATERIALS AND METHODS}

\section{Materials}

Caco-2 was obtained from the American Type Culture Collection (Rockville, MD). Dulbecco's modified Eagle's 
medium (DMEM), nonessential amino acids, penicillin, streptomycin, gentamycin, and Hanks' balanced salt solution (HBSS) were all from Gibco Life Technologies, Inc. (Grand Island, MD). Fetal calf serum (FCS) was obtained from ICN Biomedicals, Inc. (Osaka, Japan), and type-I collagen solution was from Nitta Gelatin (Osaka). Transwell cell culture chambers $(0.4 \mu \mathrm{m}$ in pore size and $12 \mathrm{~mm}$ in diameter) and a Millicell-ERS instrument with $\mathrm{Ag} / \mathrm{AgCl}$ electrodes are purchased from Coster (Cambridge, MA) and from Nihon Millipore (Tokyo), respectively. The synthetic hexapeptide (DKIHPF) was obtained from Peptide Institute, Inc. (Osaka). Fluorescein isothiocyanate (FITC), $\beta$-Lg, and ovalbumin (OVA) were from Sigma-Aldrich (Tokyo). All other chemicals were of reagent grade.

\section{Cell Culture}

All Caco-2 cells used in this study were between 30 and 50 passages. The growth medium consisted of DMEM with $20 \%$ FCS, $1 \%$ nonessential amino acids and antibiotics (100 IU/ml penicillin, $100 \mu \mathrm{g} / \mathrm{ml}$ streptomycin and $50 \mu \mathrm{g} / \mathrm{ml}$ gentamycin). Cells were cultured at $37^{\circ} \mathrm{C}$ under a humidified $5 \% \mathrm{CO}_{2}$ atmosphere. Cells were normally grown in $75 \mathrm{~cm}^{2}$ tissue culture flasks to confluence and seeded into a transwell cell culture chamber coated with type-I collagen at a density of 2 $\times 10^{5}$ cells $/ \mathrm{cm}^{2}$.

\section{Activity Measurement}

For the evaluation of $\beta$-Lg or OVA permeability, Caco2 cells were grown onto a transwell. After 14 to 21-d of culture, transepithelial electrical resistance (TEER) was measured using a Millicell-ERS. Monolayers of Caco-2 cells were used when their TEERs were $>300$ $\mathrm{ohm} \cdot \mathrm{cm}^{2}$. Each well was placed in a cluster plate with outside medium (basolateral side, $1.5 \mathrm{ml}$ ) and inside medium (apical side, $0.5 \mathrm{ml}$ ). The cell monolayers were fed fresh medium every $24 \mathrm{~h}$. One day before the permeability measurements, the monolayer was cultured in the absence (control) or presence of a test sample. After washing twice with HBSS, $0.5 \mathrm{ml}$ of HBSS containing the test sample and FITC- $\beta$ - $\mathrm{Lg}(0.5 \mathrm{mg})$ or FITC-OVA $(0.5 \mathrm{mg})$ was added to the apical side, and $1.5 \mathrm{ml}$ of HBSS containing the test sample was added to the basolateral side. A similar procedure was carried out in the absence of the test sample as a control. The monolayers were incubated for $30 \mathrm{~min}$, after which the outside medium was collected. The concentration of FITC- $\beta$-Lg or FITC-OVA in the basolateral side was determined by measuring fluorescence intensity with a spectrophotofluorometer (Shimadzu, RF-1500) at excitation and emission wavelengths of $495 \mathrm{~nm}$ and 520

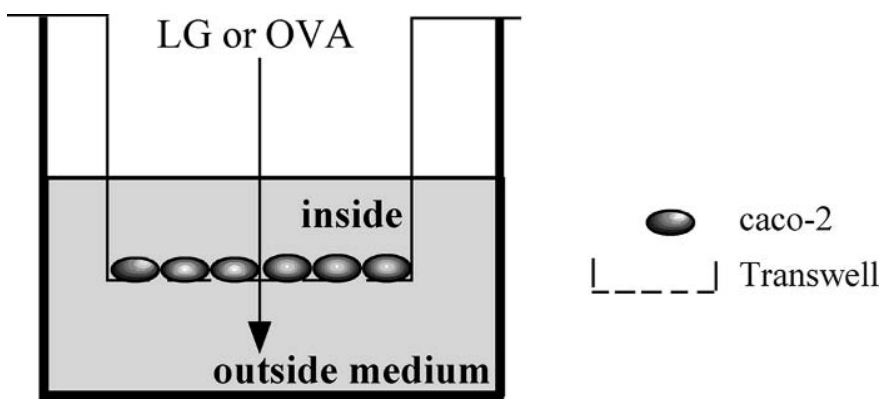

Figure 1. Schematic illustration of the evaluation of permeability using Caco-2 cells.

$\mathrm{nm}$, respectively. Inhibitory activity (\%) was calculated according to (1-A / B) $\times 100$, where $\mathrm{A}$ is the amount of $\beta$-Lg or OVA uptake in the presence of peptides, and B is that of the control. A schematic illustration of the activity measurement test using Caco-2 cells is depicted in Figure 1.

\section{FITC-labeling of $\beta$-Lg and OVA}

$\beta$-Lg and OVA were conjugated with FITC according to the method of Maeda et al. (1969). The reaction mixture was dialyzed against running water overnight, and the nondiffusible fraction was concentrated and passed through a Sephadex G-50 column to remove free FITC.

\section{Structural Analyses}

NMR experiments were conducted with a spectrometer (Bruker AMX 500), while the MS spectrum was recorded with a JEOL JMS AX-500. The N-terminal amino acid sequence of the active compound was analyzed with an amino acid sequencer (Hewlett Packard G1005A).

\section{Isolation of the Active Compound}

Edam cheese (Italian Foods, Japan; 500 g) was purchased from a market source. The cheese was crushed and then freeze-dried. The dry grits were defatted three times with $n$-hexane (500 $\mathrm{ml}$ each), and the defatted Edam cheese was extracted with 50\% methanol (1 L) overnight at ambient temperature and then centrifuged at $5000 \times g$ for $20 \mathrm{~min}$ to obtain a supernatant. The supernatant was evaporated under vacuum. The residue was dissolved in $10 \%$ methanol in $0.1 \%$ trifluoroacetic acid (TFA) $(100 \mathrm{ml})$ and the solution $(5 \mathrm{ml}$ each) was loaded onto an octadecylsilyl (ODS) column (Waters, Sep-Pak C18). The column was washed with $10 \%$ methanol in $0.1 \%$ TFA $(10 \mathrm{ml})$ and then eluted with $80 \%$ methanol in $0.1 \%$ TFA $(5 \mathrm{ml})$. The fraction adsorbed 
by ODS and eluted with $80 \%$ methanol was further fractionated by a first HPLC step on a reversed phase column (Shodex RSpak PR18-415, 4.6 × $150 \mathrm{~mm}$ ). Gradient elution was done starting with $10 \%$ methanol in $0.1 \%$ TFA and ending with $90 \%$ methanol in $0.1 \%$ TFA at a flow rate of $1 \mathrm{ml} / \mathrm{min}$ at $20^{\circ} \mathrm{C}$. Peaks were detected at a wavelength of $220 \mathrm{~nm}$. The peaks were dried and submitted to activity measurement assay. The active peak was fractionated by a second HPLC step with elution by 20 to $40 \%$ (gradient) methanol in $10 \mathrm{mM}$ ammonium acetate, other conditions being the same as in the first HPLC step. The active peak obtained by the second HPLC step was desalted under the same conditions as in the first step. The peak was evaporated under vacuum and then stored on $\mathrm{NaOH}$ to remove remaining TFA.

\section{SDS-PAGE}

In order to examine the molecular size distribution in the basolateral side medium, the medium $(0.25 \mathrm{ml})$ was freeze-dried and separated by $12.5 \%$ SDS-PAGE by the ordinary method. The fluorescence intensity was visualized using a fluoroimager (Amersham, STORM 860)

\section{RESULTS AND DISCUSSION}

Undigested allergen uptake in the intestine is the first and crucial step in triggering food allergy. Thus, regulating allergic disease would be possible if allergen uptake could be inhibited. For this purpose, we screened for a substance with the ability to inhibit allergen uptake from dairy products. It is highly likely that many kinds of bioactive compounds are produced in cheese during fermentation by microorganisms. Therefore, we selected Edam cheese as the starting material in this study.

The crude extract of Edam cheese was fractionated on a Sep-Pak-C18 cartridge. In the activity measurement assay, activity was detected in the $80 \%$ methanol-eluted fraction. This fraction was further purified by reversephase HPLC, and the asterisked peak (Figure 2A) was obtained as an active fraction. This peak was then subjected to a second HPLC, and the asterisked peak (Figure 2B) was found to be active. The active compound was obtained as a powder (about $50 \mathrm{mg}$ ) from the starting material cheese (500 g).

The ${ }^{1} \mathrm{H}-\mathrm{NMR}$ spectrum of the active compound indicates its peptide nature. Six $\alpha$ protons for each amino acid residue were observed and the side-chain proton networks could be followed by $2 \mathrm{D}$ COSY. The characteristic proton sequences of $\delta 4.08-1.79(-0.80)-1.17 / 1.39$ $0.84, \delta 4.42-1.93 / 2.17-1.88 / 1.96-3.56 / 3.71$ and $\delta 4.73-$
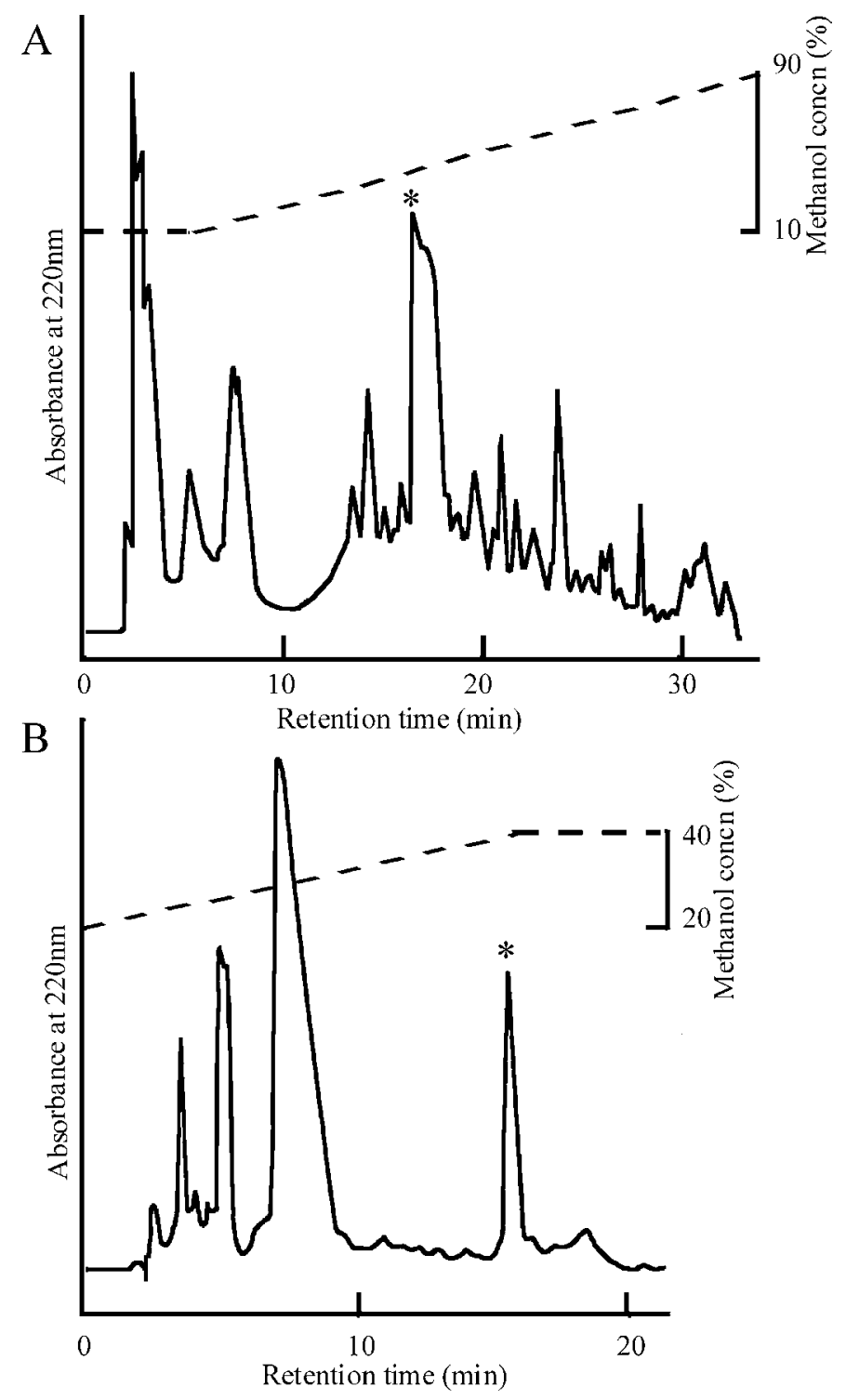

Figure 2. HPLC profiles of the active fraction obtained by fractionation (A) and that obtained from the first HPLC (B).

1.75/1.79-1.39-1.68-2.98 show the presence of Ile, Pro and Lys, respectively. The additional ABX patterns of $\delta$ 4.46-3.03/3.18 and $\delta$ 4.93-3.05/3.09 indicate Phe and His residues, taking into account the low-field protons of a monosubstituted benzene at $\delta$ 7.27-7.37-7.29 and an imidazole at $\delta 7.13$ and 8.12, respectively. Finally, the sequence of $\delta 4.21-2.72 / 2.82$ could be assigned to Asp from the following mass spectral data. The FAB mass spectrum of the compound gave an $[\mathrm{M}+\mathrm{H}]^{+}$ion at $m / z 756$ together with peaks of $m / z 778\left([\mathrm{M}+\mathrm{Na}]^{+}\right), 800$ $\left([\mathrm{M}-\mathrm{H}+2 \mathrm{Na}]^{+}\right)$and $822\left([\mathrm{M}-2 \mathrm{H}+3 \mathrm{Na}]^{+}\right)$, which agrees with the molecular formula of $\mathrm{C}_{36} \mathrm{H}_{53} \mathrm{~N}_{9} \mathrm{O}_{9}$ (755), indicating a hexapeptide of Ile, Pro, Lys, Phe, His, and Asp. 


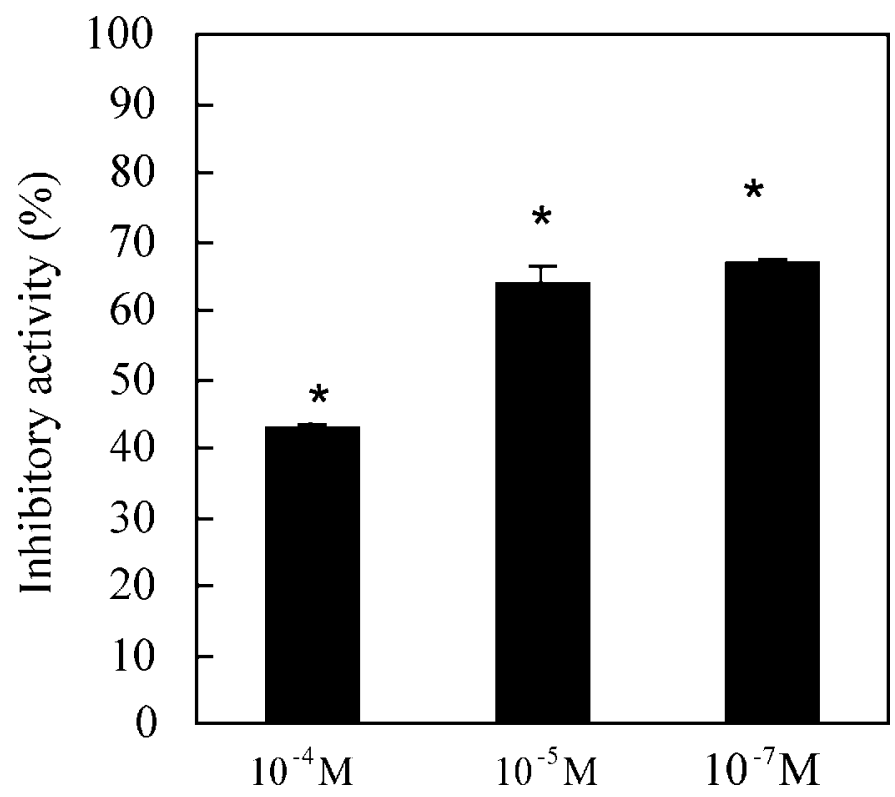

Figure 3. Effect of the hexapeptide on permeability of $\beta$ - $\mathrm{Lg}$ through Caco-2 monolayers. Data bars represent the means $\pm \mathrm{SE}$. $\mathrm{SE}$ of the control was \pm 9 . Not significantly different $(P<0.05)$ from the control sample at $10^{-8} M$ of hexapeptide. *Significantly different $(P<0.05)$ from the control sample.

Next, the active compound ( $1 \mathrm{mg})$ was submitted to primary structure determination. The determined structure was Asp-Lys-Ile-His-Pro. Amino acid sequence similarity between the active compound and other known proteins was checked using a sequence search program (ProteoMetrics). The primary structure of the active compound agrees with the amino acid sequence of residues 47-51 of $\beta$-casein, the $52 \mathrm{nd}$ amino acid residue of the peptide being Phe. Putting together the analytical data, we identified the active compound as Asp-Lys-Ile-His-Pro-Phe.

The activity-concentration relationship was evaluated using the synthesized hexapeptide and a Caco-2 monolayer. The permeability of $\beta-\mathrm{Lg}$ is expressed relative to the control values (Figure 3 ). Treatment with the hexapeptide $\left(10^{-5} M\right)$ significantly $(P<0.05)$ decreased the $\beta$-Lg permeability. At a low concentration $\left(10^{-7} \mathrm{M}\right)$ of hexapeptide, the same activity was observed as that obtained at $10^{-5} M$. Because the hexapeptide did not change the TEER values (data not shown), the data suggest that the suppression of $\beta$-Lg uptake by the hexapeptide is not associated with a modification of tight-junction permeability. However, the inhibitory activity was diminished at $10^{-4} \mathrm{M}$ and at $10^{-8} \mathrm{M}$. One possibility for explaining these phenomena is that, in Caco-2 cells model, relatively high dose of the peptide might be recognized as a signal for ingested nutrients, and might trigger a $\beta$-Lg uptake.

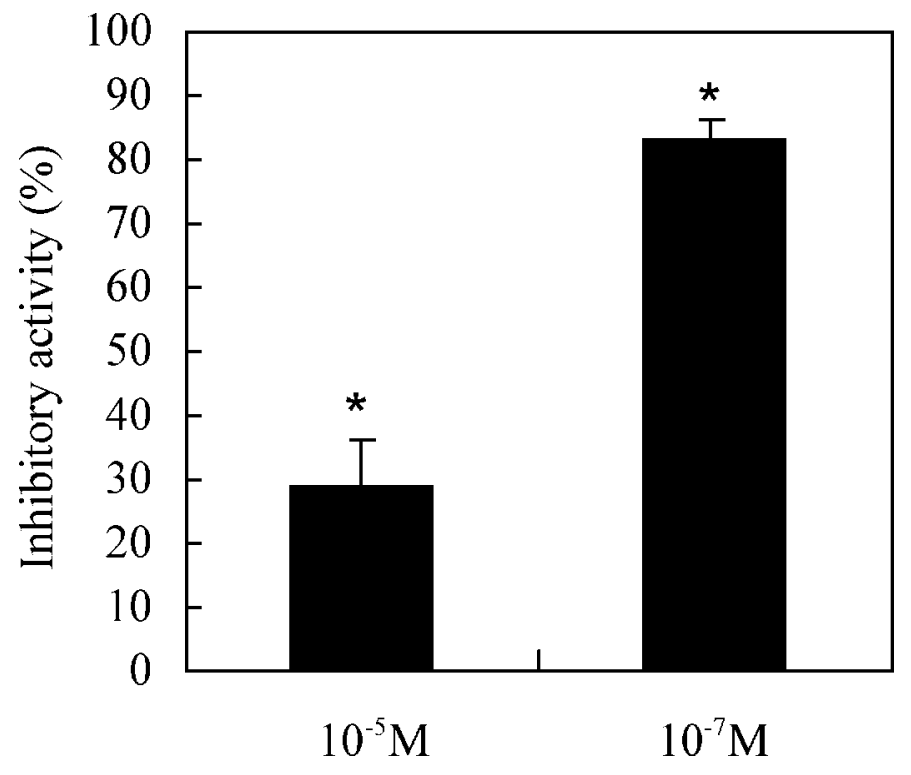

Figure 4. Effect of the hexapeptide on permeability of OVA through Caco-2 monolayers. Data bars represent the means $\pm \mathrm{SE}$. $\mathrm{SE}$ of the control was \pm 0.3 . Not significantly different $(P<0.05)$ from the control sample at $10^{-4}$ and $10^{-8} M$ of hexapeptide. *Significantly different $(P<0.05)$ from the control sample.

There are various kinds of physiologically functional (bioactive) peptides derived from milk protein, and these have been the subject of intensive studies (Jelen and Lutz, 1998). For example, the most important casein-derived peptides are casomorphins, which possess opioid-like activity; immunopeptides, which have an immunostimulating activity; peptides with antihypertensive activity; and phosphopeptides with the ability to sequester calcium and possibly other minerals, thus acting as biocarriers (Jelen and Lutz, 1998). The hexapeptide Asp-Lys-Ile-His-Pro-Phe, identified in this study, should be also added to the list of milk proteinderived and physiologically functional peptides.

In addition, this study presents a novel significance of lactation, which is that the lactation has a novel important role, that is, preventing protein (allergen) invasion in the small intestine. In order to clarify this hypothesis, we next investigated whether Asp-Lys-IleHis-Pro-Phe inhibits the uptake of OVA, the most common food allergen. As shown in Figure 4, the hexapeptide also shows a remarkable inhibitory activty of OVA transport at a concentration of $10^{-5} \mathrm{M}$ to $10^{-7} \mathrm{M}$.

We also analyzed the molecular size distribution in the basolateral side medium by SDS-PAGE with fluorescence detection as in Figure 5. If $\beta$ - $\mathrm{Lg}$ and OVA would be degraded into peptides by proteases of Caco2 cells, it would be possible that Asp-Lys-Ile-His-ProPhe inhibited the digesting proteases and subsequently lead to the decrease of fluorescence intensity. However, 


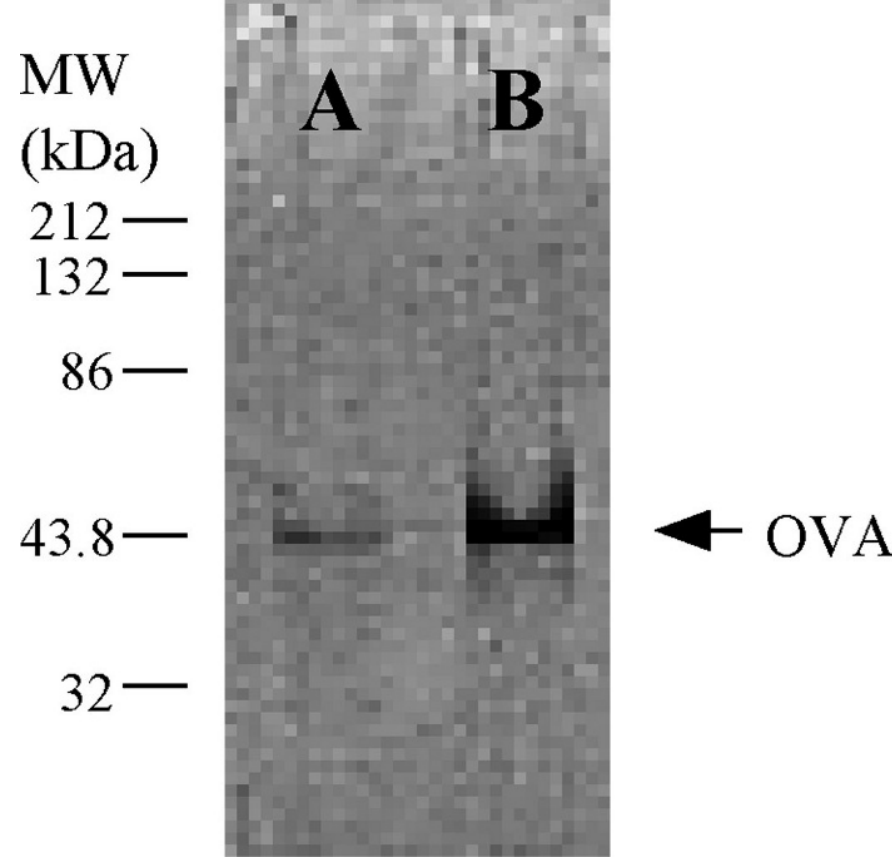

Figure 5. SDS-PAGE analysis of the basolateral side medium. The basolateral medium was freeze-dried and separated 12.5\% SDSPAGE with fluorescence detection. (A) culture with $10^{-7} M$ of AsnLys-Ile-His-Pro-Phe (B) culture without the peptide. In both cases, OVA was transported almost as an intact form.

OVA was transported through Caco-2 cell monolayer as almost an intact form (Figure 5). Thus, it is assumed that the peptide directly inhibited uptake of OVA. And, the suitability of the Caco-2 as a model for allergic infant intestinal tract was here supported by the fact that the most of OVA was passed as an intact form. (Although we also tried to examine $\beta$-Lg transport by the same SDS-PAGE analysis, it was difficult to visualize because very little $\beta$-Lg was transported.) Future work will be designed to clarify the mechanisms by which the $\beta$-casein derived peptide inhibits allergen uptake.

In conclusion, it was confirmed that a $\beta$-casein derived peptide, Asp-Lys-Ile-His-Pro-Phe, inhibits the uptake of $\beta-\mathrm{Lg}$ as well as OVA. A means to apply this peptide to the prevention of milk allergy is now being planned using an animal model.
The human $\beta$-casein amino acid sequence has a highly-homologous peptide, Asp-Lys-Ile-Tyr-Pro-SerPhe, at almost the same position as bovine $\beta$-casein hexapeptide. Although it remains to be evaluated if the Asp-Lys-Ile-Tyr-Pro-Ser-Phe peptide from human $\beta$-casein would have an activity similar to that of Asp-LysIle-His-Pro-Phe, it is highly possible that an anti-allergenic peptide such as Asp-Lys-Ile-Tyr-Pro-Ser-Phe is produced from $\beta$-casein by proteases in infants and could prevent allergen invasion.

\section{REFERENCES}

Bahna, S. L. 1985. Pathogenesis of milk hypersensitivity. Immunol. Today 6:153-154.

Hidalgo, I. J., T. J. Raub, and R. T. Borchardt. 1989. Characterization of the human colon cell line (Caco-2) as a model system for the intestinal epithelial permeability. Gastroenterol. 96:736-749.

Jalonen, T. 1991. Identical intestinal permeability changes in children with different clinical manifestations of cow's milk allergy. J. Allergy Clin. Immunol. 88:737-742.

Jelen P., and S. Lutz. 1998. Functional milk and dairy products. Pages 365-367 in Functional Foods: Biochemical \& Processing Aspects. G. Mazza ed., Technomic Publishing Company, Pennsylvania.

Kaminogawa, S., S. Hachimura, H. Nakajima-Adachi, and M. Totsuka. 1999. Food allergens and mucosal immune systems with special reference to recognition of food allergens by gut-associated lymphoid tissue. Allergol. Int. 48:15-23.

Kuwata, T., A. M. Pham, C. Y. Ma, and S. Nakai. 1985. Elimination of $\beta$-lactoglobulin from whey to simulate human milk protein. J. Food Sci. 50:605-609.

Lebental, E. 1975. Cows milk protein allergy. Pediatr. Clin. North Am. 22:827-833.

Maeda, H., N. Ishida, H. Kawauchi, and K. Tsujimura. 1969. Reaction of fluorescein isothiocyanate with proteins and amino acids. J. Biochem. 65:777-783.

Mate, J. I., and J. M. Krochta. 1994. $\beta$-Lactoglobulin separation from whey protein isolate on a large scale. J. Food Sci. 59:1111-1114.

Merritt, R. J., M. Carter, M. Haight, and L. D. Eisenberg. 1990. Whey protein hydrolysate formula for infants with gastrointestinal intolerance to cow milk and soy protein in infant formulas. J. Pediatr. Gastoenterol. Nutr. 11:78-82.

Pinto, M., S. Robine-Leon, M. D. Appay, M. Kedinger, N. Triadou, E. Dussaulx, E. Lacroix, P. Simon-Assmann, K. Haffen, J. Fogh, and A. Zweibaum. 1983. Enterocyte-like differentiation and polarization of the human colon carcinoma cell line Caco-2 in culture. Biol. Cell. 47:323-330.

Savilahti, E., and M. Kuitunen. 1992. Allergenicity of cow milk proteins. J. Pediatr. 121:S12-S20.

Takahashi, T., S. Kaminogawa, T. Kuwata, O. Ando, and K.Yamauchi, 1988. T cell recognition of $\beta$-lactoglobulin. Agric. Biol. Chem. 52:2485-2491.

Takahashi, T., K. Yamauchi, and S. Kaminogawa. 1990. Comparison between the antigenicity of native and unfolded $\beta$-lactoglobulin. Agric. Biol. Chem. 54:691-697.

Tsuji, N. M., J. Kurisaki, K. Mizumachi, and S. Kaminogawa. 1993. Localization of T-cell determinants on bovine $\beta$-lactoglobulin. Immunol. Lett. 37:215-221. 